\title{
Article
}

\section{The germs of terror - Bioterrorism and science communication after September 11}

\author{
Maria Chiara Montani
}

The attacks of September 112001 and in particular, the sending of letters containing anthrax spores the following October had a profound effect on society, and at the same time on science and its communicative mechanisms. Through a quanto-qualitative analysis of articles taken from four publications: two daily newspapers, the Corriere della Sera from Italy and the New York Times from the United States and two science magazines, Science and Nature, we have shown how the aforementioned events provoked the emergence of media attention regarding bioterrorism. A closer reading of the articles shows that today, science - including that found in science magazines - is closely related to politics, economics and the debate over the freedom to practice communicate. The very mechanisms of communication between scientists were changed as a result of this debate, as can be seen from the signing of the Denver Declaration in February 2003, which brought about the preventative selfcensorship of publication of biomedical research findings.

\section{Introduction}

The events of and following September, 112001 have had strong repercussions on science, regarding both its public image and the mechanisms of science communication. The objective of the present study is to investigate how and when bioterrorism and, as a result, science was mentioned in the press. This was carried out through the analysis of two daily newspapers the Corriere della Sera and the New York Times and two science magazines Science and Nature, in order to verify what has changed from a communicative point of view following September 11.

One of the most striking results of the circulation of anthrax spores via mail in the following October and the growing fears of attacks using biological weapons was scientists' decision for preventative selfcensorship in February 2003.

Scientists in the United States had to face up to a communicative state of emergency which made them targets for criticism and accusations and forced them to look for new strategies for collaboration between such diverse fields as politics, economics and science.

According to the German sociologist Ulrich Beck, the implosion of the Twin Towers has been followed by an «explosion of silence», thanks to the lack of concepts and words suitable to express the western world's feelings. Moreover, Beck refers to this situation following September 11 as a «collapse of language». ${ }^{1}$ The very language, concepts and words used during and about September 11 about bioterrorism are the subject of our research.

\section{Methodology}

In order to shed light on the diverse mechanisms of communication at work regarding bioterrorism, a comparison was made between two very diverse media: daily newspapers and science magazines.

Moreover, to be able to understand how the images of events presented in Italy differed from those in the States (as the Worldviews $2002^{2}$ report of the Chicago Council on Foreign Relations and the German Marshall fund, which takes a picture of American's and European's view of the world post September 11 both imply), attention was focussed on two newspapers that are considered to be opinion leading in the respective countries: the Corriere della Sera for Italy, the New York Times for the United States. 
By opinion leading we refer to outlets that are read by decision makers for information and by other journalists for inspiration: they are considered to influence the public sphere, as well as to mirror national attitudes. Opinion leading press is the privileged information source for a country's ruling class and moulds its public opinion. Therefore, an analysis based on opinion leader press can be used in an attempt to gain an understanding of the transformations within societies and nations involved. ${ }^{3}$

To study the position taken by scientists in this regard and to monitor the dynamics that brought about preventative self-censorship, we carried out an analysis of the two most important international science magazines: Science and Nature.

Both for the newspapers and science magazines, the analysis is divided into two basic parts: in the first phase, the electronic archives of the various publications were searched for articles containing the keyword 'bioterrorism', in order to obtain a rough guide of when this topic was mentioned.

To be specific, the respective searches were carried out in the on-line archives: the Corriere della Sera archive is available from January 1992, the New York Times from January 1996, Science from October 1995. The Nature electronic archive dates back to 1987 but, as with Science, the search was run from October 1995. The digital archives were used for a primary quantitative analysis of the media coverage concerning bioterrorism and the effects of the events of September and October 2001.

Here we can observe a typical journalistic process at work: a steep increase in articles written after September 11 and a gradual drop off in interest; the articles in the two magazines also increase at the end of 2001, but in this case, interest in the topic remains constant at least until the ratification of the Denver Declaration (February 2003).

It was seen, therefore, figure 17nd figure 2 that the Sept 11 Twin Towers attack and the biological attack with the anthrax spores via mail on the following October introduced bioterrorism to the journalist's agenda and reinforced the attention given to these topics in science magazines.

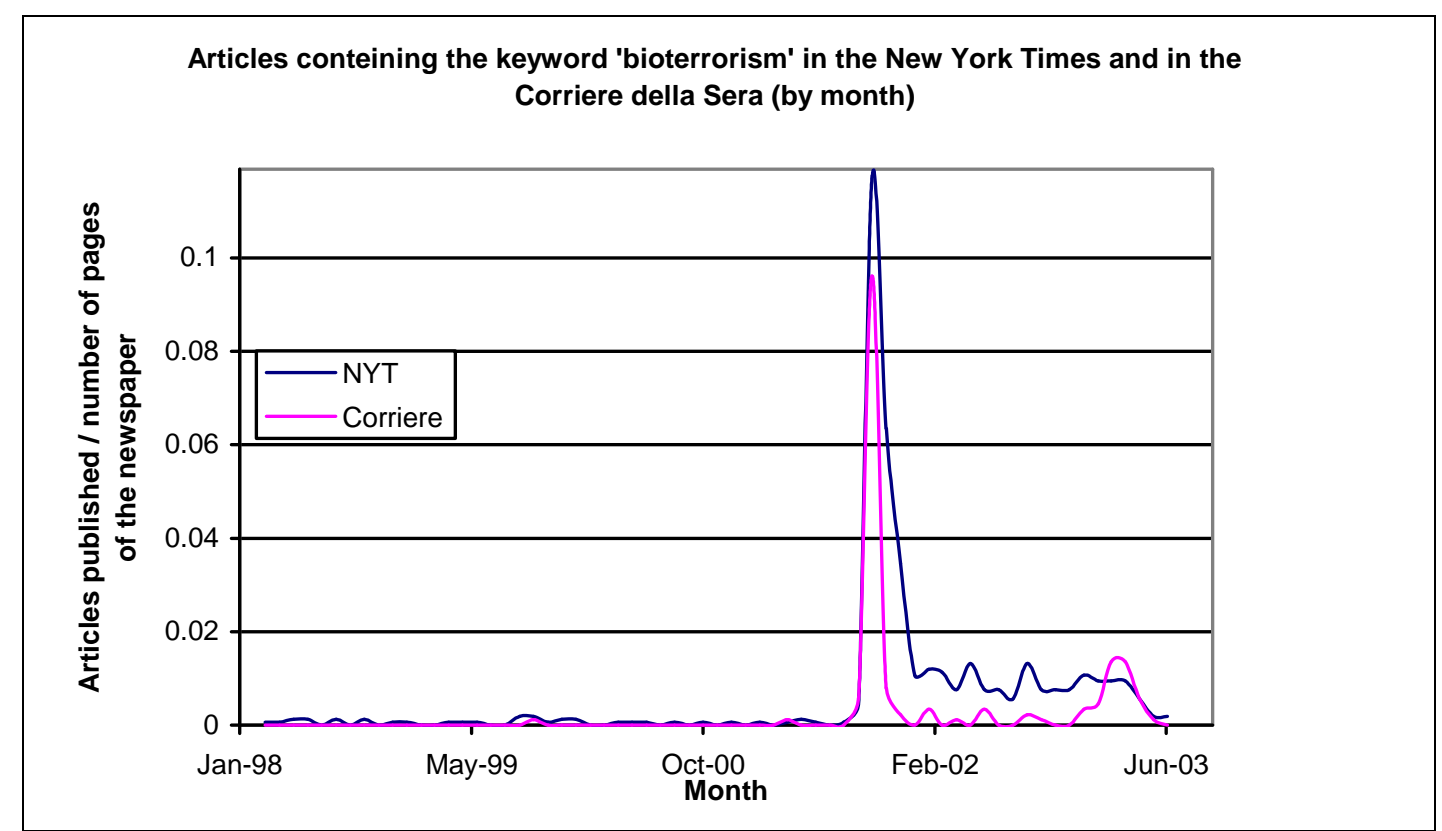

Figure 1. Search results from two newspapers. Per an easier reading, the dates start from January 1998. As the number of pages of New York Times is different from Corriere della sera, we normalized the number of articles respect the number of the pages, in order to have a significant comparison. 


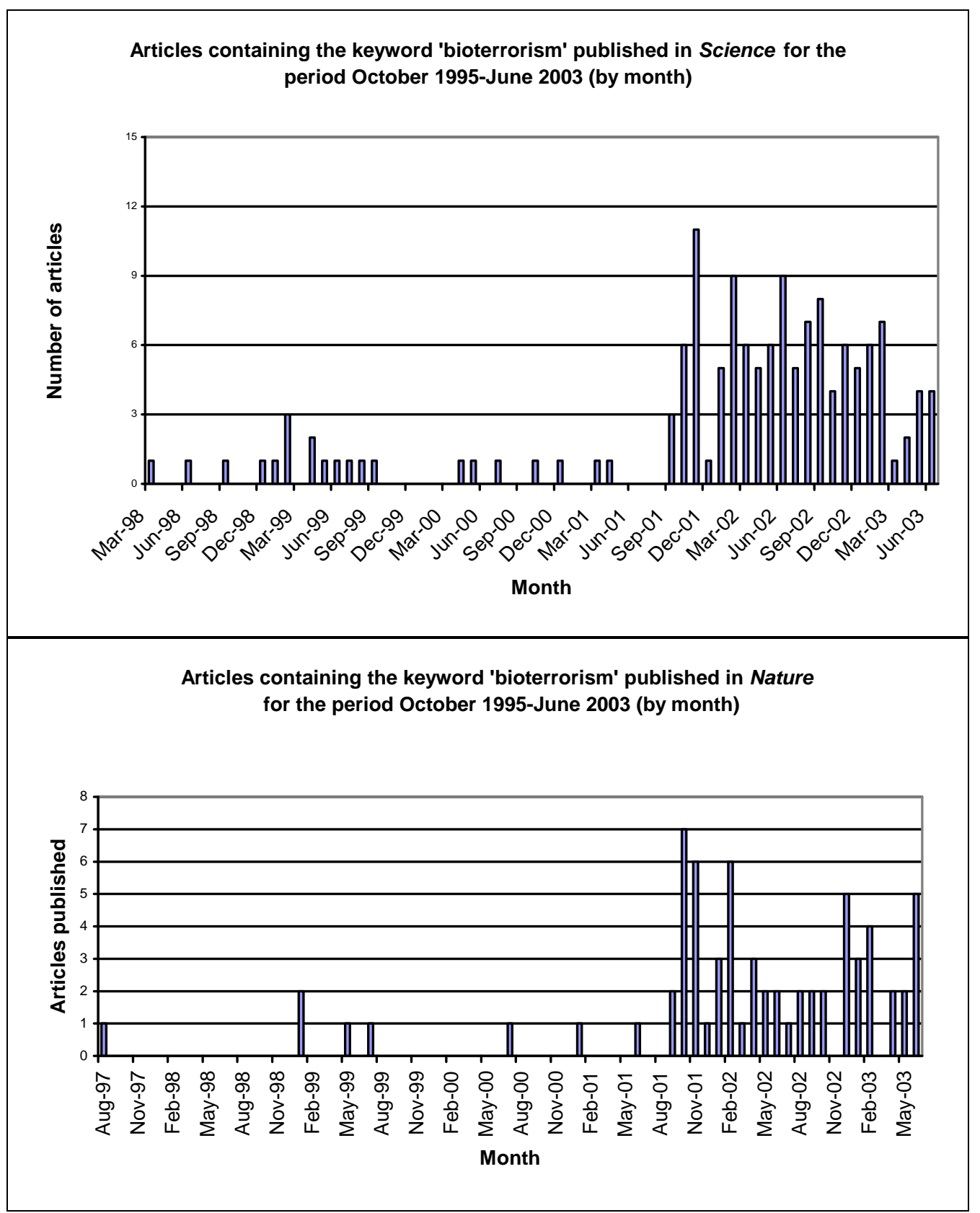

Figure 2. Research results from Science and Nature for the keyword 'bioterrorism'. Per an easier reading, the dates start from the first published article.

\section{Qualitative analysis}

The qualitative research has been made after the choice of a precise temporal range (based on data from the quantitative analysis).

For the articles in the Corriere della Sera and in the New York Times, a decision was taken to carry out a qualitative analysis of articles published only during the crisis period since, as mentioned before, journalistic interest in the issue gradually dropped off until it received only a salutary mention in the newspapers. The most significant periods from the quantitative analysis were taken into consideration: 


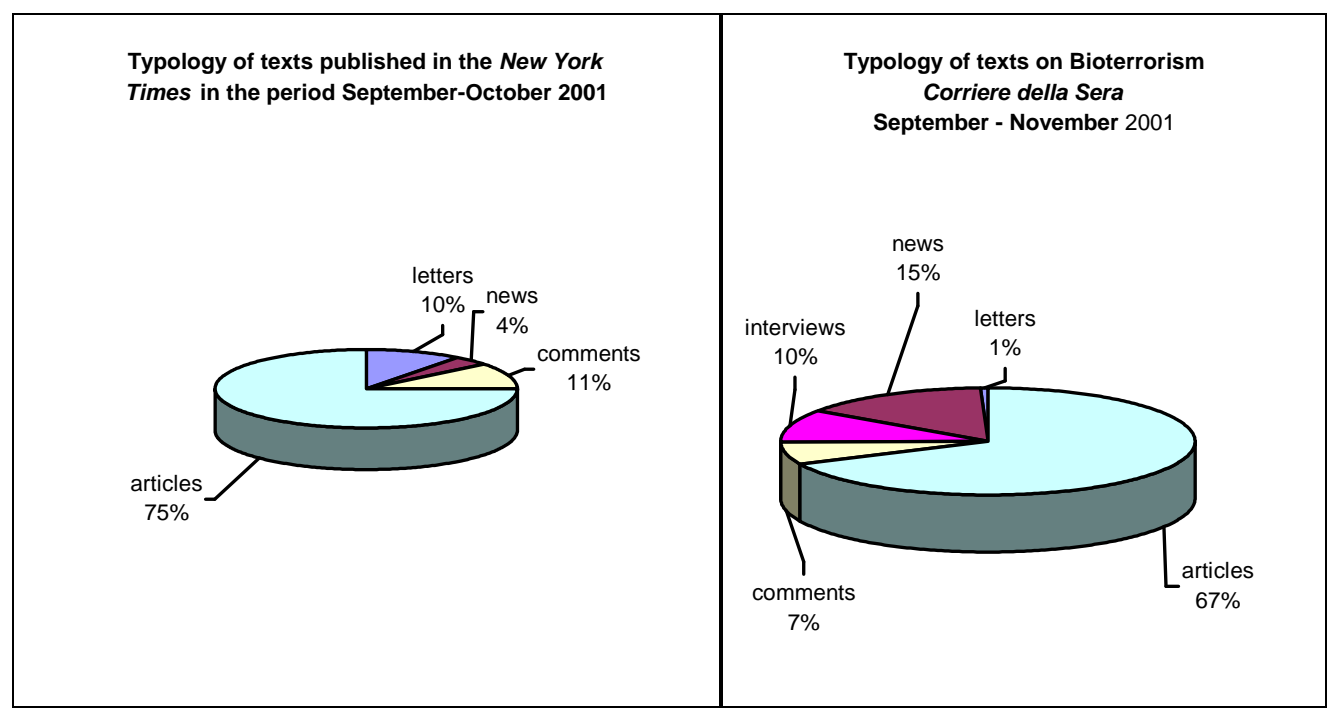

Figure 3. Typology of the extracts from the two newspapers.

September - October 2001 for the New York Times and September - November 2001 for the Corriere della Sera.

Instead, in an attempt to better chart the evolution of new methods of carrying out and communicating science, the relationships between scientists and politicians and reflections on freedoms in science and self-censorship, it was decided to make a qualitative analysis of all the articles collected from Science and Nature in the former quantitative analysis.

The texts were read and classified monitoring: their typology (articles, news, comments, letters and interviews) and the narrative frames.

\section{Typology of the extracts}

There were no interviews in the New York Times: in US journalism, in order to guarantee correctness and impartiality of information, there is a tendency to present several viewpoints in each article. During the conference 'The Anthrax Scare and Bioterrorism', ${ }^{4}$ organised by The Brooking Institution during a project entitled "The Role of the Press in the Anti-Terrorism Campaign", the Washington Post journalist

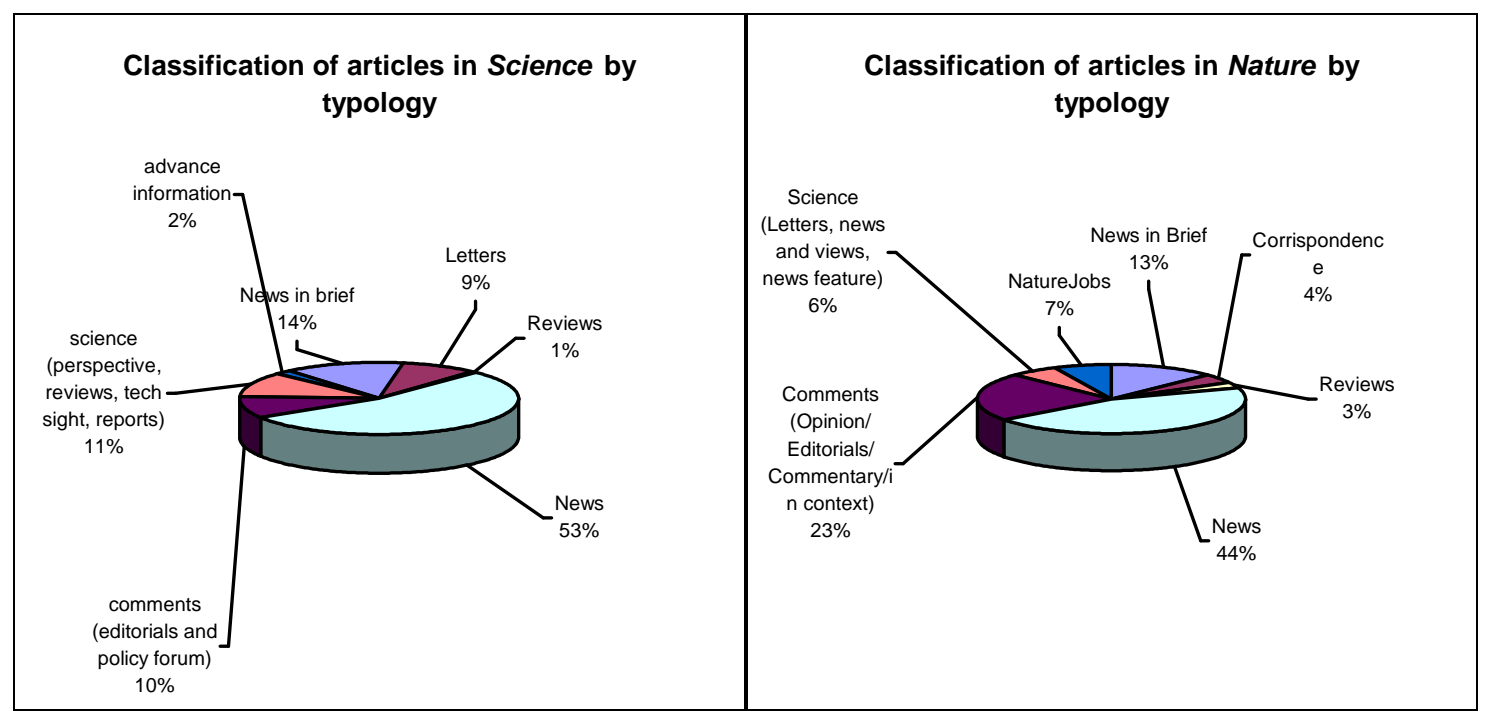

Figure 4. Typology of texts in magazines. 
Ceci Connolly explains this choice by saying that there is very little coordination between scientists and politicians and therefore no official, authoritative voice to report. Other than news articles and analysis, a large part of the New York Times is made up of reader's comments and letters: the city's population are personally involved in the debate on bioterrorism.

On the other hand, in the Corriere della Sera there is only one letter and few comments, whereas interviews have some importance. The prevalence of brief news items and articles in the Italian daily compared to those in the American can be justified by the difficulty in accessing direct sources and the probable greater dependency on releases from press agencies. The New York Times, due to its presence in the field and for the increased availability of people and means, is able to go into more depth.

In Science the majority of the texts are news and articles, written by journalists on the editorial staff, who report news items regarding science and the scientific community, or the voices of scientists and politicians: almost $70 \%$ of the total is made up of news and news in brief sections. Bioterrorism, therefore, takes up a large part of the news items, as well as those 'made to measure' for scientists. If we classify these articles by typology, however, science slightly overtakes pieces with comment and reflection. Articles with reflection and comment on science (23\% vs $10 \%)$ can be found in greater number in Nature than Science. This may be because Nature is not published in the US and therefore is at a distance and has more space for reflection.

\section{Narrative frames}

In order to understand how the bioterrorism emergency was reported, it is useful to divide the articles that are relevant for qualitative analysis into narrative frames: macro-themes can be identified that can be used as umbrella terms for giving each article a precise "interpretative frame". For a few articles, in which different themes were present, a fraction of the article was assigned to different frames.

For the New York Times and the Corriere della Sera, four macro-frames have been identified: political; economic; health; security.

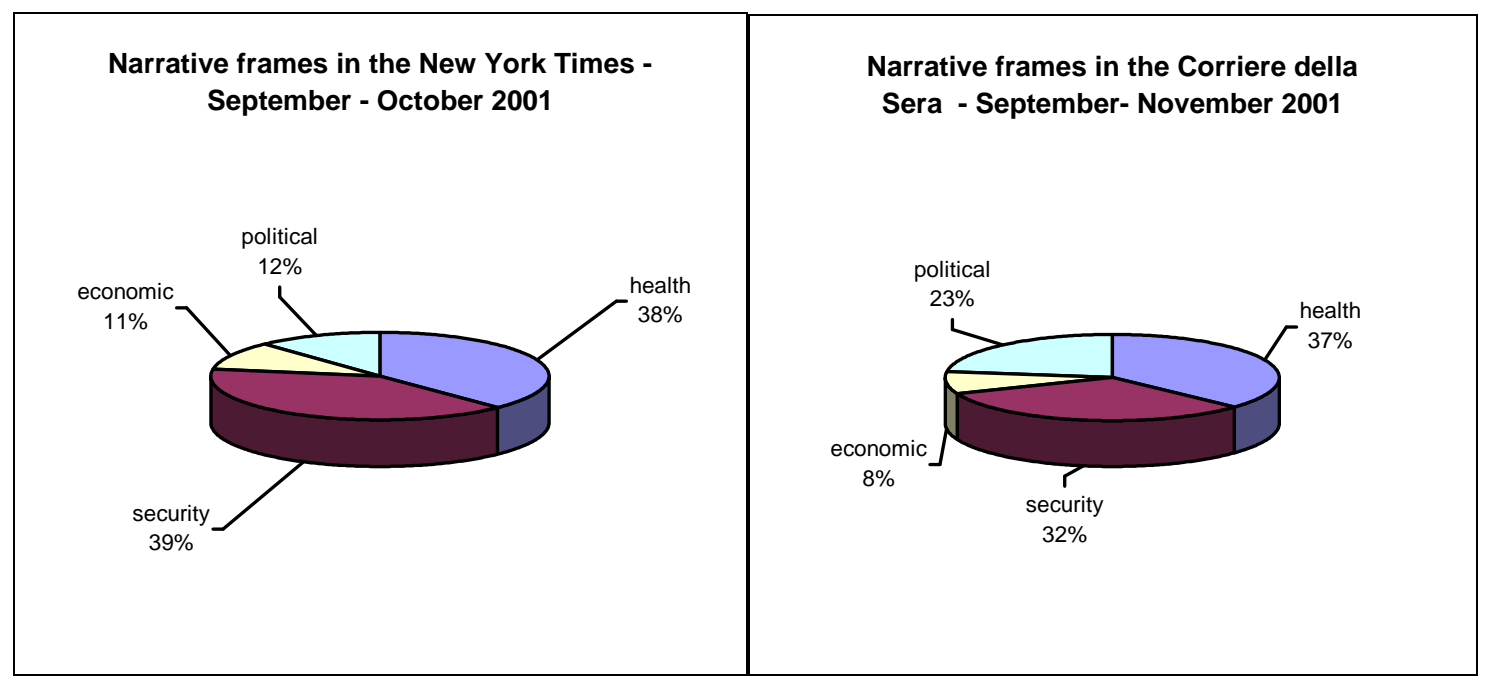

Figure 5. Distribution of narrative frames for the New York Times and the Corriere della Sera.

From these figures we can conclude that the implications for health and public security make most news, which is understandable and predictable given that they deal with illnesses and terrorist actions to combat and avoid. It could also be that the presence on the editorial staff of the US newspaper of the three authors of the book Germs has favoured this choice, as they themselves seem to suggest in their preface. ${ }^{5}$

The political frame is more important for the Corriere della Sera than for the New York Times. As far as the percentages for the economic frame are concerned, $11 \%$ in the New York Times against $8 \%$ in the Corriere della Sera can be explained by the fact that the States are also responding to an economic 
emergency: following on from the insurance and airline industry, the postal service is also facing a crisis and the controversy over Bayer's exclusive production rights of Cipro creates much more heated debate in the States than in Italy.

The science mentioned in the articles is of a practical nature, seen in an instrumental way: there is information about protection against pathogenic agents, news regarding possible vaccines or antibiotics, or the medical reports of victims, and there are very few articles with an exclusively scientific aim. Instead, science takes on a relevant role in the journalistic tools that accompany the articles, explanatory information boxes and tables: it almost seems as though science is put in a corner, available only to those interested, as though journalistic language cannot be married with scientific language and should therefore be kept apart from it.

The narrative frames for the science magazines are slightly different: politics (national and international); research policy; health; security; ethics (freedom within science, freedom to communicate science); science; economics.

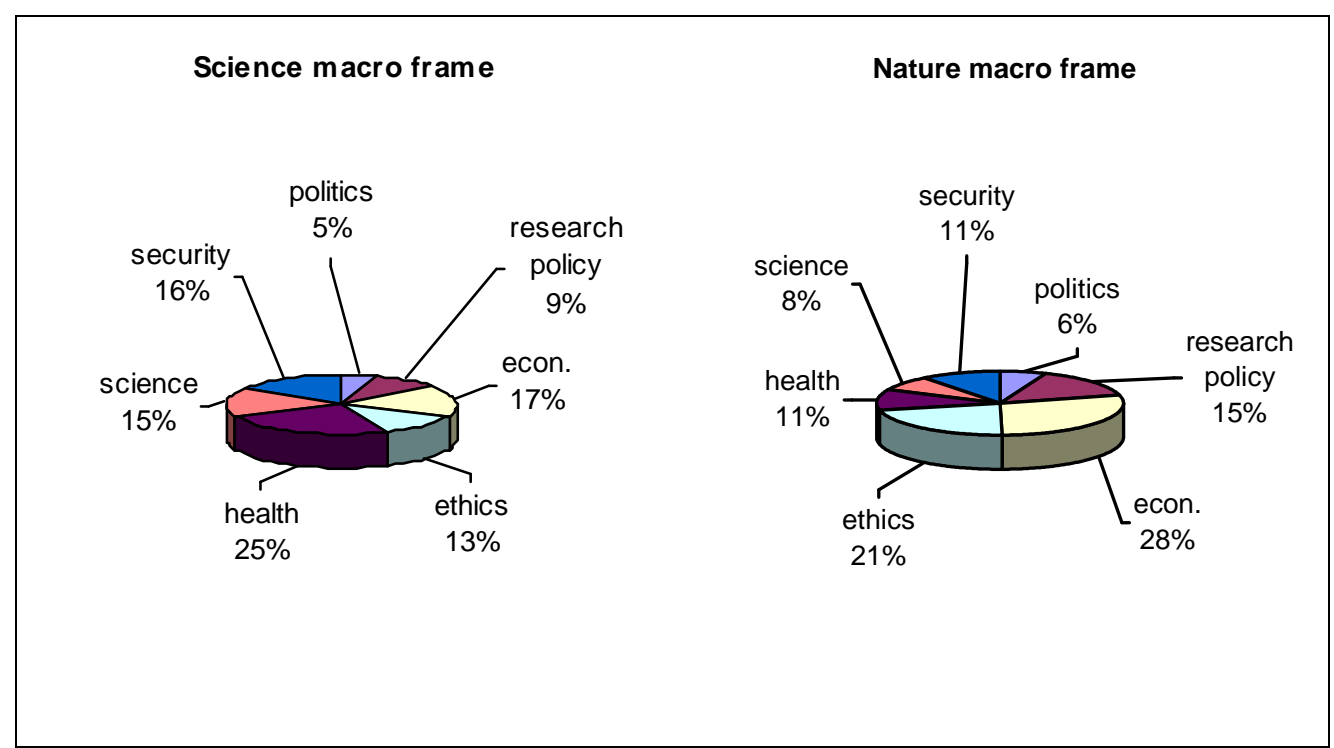

Figure 6. Distribution of narrative frames for Science and Nature.

As the figures show, Science and Nature do not consider bioterrorism as being a solely scientific theme, but a topic that has strong political, economic and ethical implications.

In particular, both magazines talk about governmental research funding and the need for a high level of collaboration between political and health authorities. ${ }^{6}$ The increased focus in Nature on less scientificsanitary implications of the bioterrorism emergency, but rather those which are political, economic and ethical, can probably be explained by the greater objectivity a European magazine can achieve regarding a threat aimed at the United States, looking more at the general consequences on the practice of science and the free circulation of ideas. The theme of preventative self-censorship is well debated in Nature: whilst in Science it is not dealt with until 26 April 2002, the British magazine looks at the theme from 15 November 2001, when some scientists start to gain awareness that some research findings could be considered beneficial to terrorists and could therefore be subject to restriction on the part of the United States government. ${ }^{7}$ The scientific community asks questions about the possible effects this may have on research and how to prevent sensitive information from falling into the hands of terrorists, avoiding public accusations at the same time; ${ }^{8}$ between the lines in Nature the attempts of the American government to intervene in the regulation of the free circulation of scientific ideas that are considered as "sensitive homeland security information", is very clear and explicit (much more so than in Science), and a 'prise de conscience' is necessary on the part of the scientists. 


\section{Conclusions}

With our analysis, we have shown how bioterrorism has awakened interest in both public opinion and within the scientific community. In fact, following September 11, social actors from diverse fields were involved in the anthrax case.

In particular, politics, ethics and economics feature more significantly in communication about bioterrorism. Whilst in the newspapers, politics and economics are present in over 30\% of the articles published directly after September 2001, in Science $22 \%$ of the total number of articles published over the period spanning October 1995 - June 2003 deal with politics and economics and indeed in Nature, the figure reaches 34\%. Scientists themselves felt the weighty presence of politics in the specialist magazines, something which in April 2003 brought about a debate regarding the contamination between science and politics in the British Medical Journal as a result of questions regarding communication featured in medical journals. ${ }^{10,11,12,13,14}$

The events of September 11 were an extraordinary media watershed: prior to this date in the Corriere della Sera, for example, only two articles were published containing the word 'bioterrorism', and in all cases the maximum number of articles was registered after the circulation of letters containing anthrax spores in October 2001.

In the newspapers, a great deal of space was dedicated to relating the details of the news stories, even though in the New York Times there are comments and editorials that aim to deal with the problem of bioterrorism from all points of view. Both for the dailies and the science magazines, bioterrorism is not just a topic regarding science or health, but it also has multiple social and economic implications connected to security and a reflection on the practice and communication of science. Scientists being called on to give suggestions to politicians, the Ministry producing guidelines for doctors, the controversy over the patent for Cipro, the discussions regarding the scarcity of investment in the production of vaccines are all examples of how today science is heavily contaminated by the requests that society makes of it. ${ }^{15}$

One of the most crucial points of analysis was the crisis in communication between scientists, which brought about the scientific community's decision to practice preventative self-censorship when publishing results in the field of biomedicine, unthinkable before September $11 .{ }^{16} \mathrm{Up}$ until February 2003, the date of the Denver Declaration, reflections on the free circulation of research findings follow one after the other in the two science magazines (in Nature in particular). ${ }^{8,17,18,19}$ In these articles, scientists voice their concerns over governmental pressure on the possible use of scientific work on the part of terrorist groups ${ }^{7,8,9,20,21}$ and they look for a solution to safeguard the autonomy of scientific magazines.

Before 2003, according to Ronald Atlas, the American Society for Microbiology refused only two articles, then published after some modifications: it is clear that the fear of external interference, and not a real need of censorship, was one of the most significant stimuli for those promoting self-censorship. Moreover, the fact that the debate continued after February 2003 is certainly an indicator of a new awareness on the part of the scientists, who want to keep communicative methods under their own control. ${ }^{19,22,23}$

Institutional communication also came in for much criticism: the anthrax emergency was an opportunity for the American government to rethink the role of its scientific advisors and to build new links between the scientific and politico-administrative communities. ${ }^{4,6,24,25,26}$

As underlined in Nature, with the anthrax spores, after physics and chemistry, even biology has been put to use: ${ }^{7}$ today fears regarding the use of medical and biological knowledge in warfare are no longer unjustified. It is nevertheless important to underline that, from the pages of Science and Nature, it is clear that scientists are determined not to let this happen, as they showed with the position they have taken regarding preventative self-censorship. ${ }^{27}$

\section{Notes and references}

\footnotetext{
${ }^{1}$ Beck U. (February 2002). The Terrorist Threat: World Risk Society Revisited, Public Lecture at the London School of Economics and Political Science.

${ }^{2}$ On line at <http://www.worldviews.org>

3 Bauer M.W., Gaskell G. (2001) Qualitative Researching With Text, Image And Sounds. A Practical Handbook, Sage Publication.
} 
4 Brooking Institution (19 December 2001). The Anthrax Scare and Bioterrorism, from <http://www.brookings.edu/gs/projects/press/Press.htm>.

5 Broad W., Engelberg S., Miller J. (2002). Germi, Longanesi.

6 "Anti-terrorist Agendas" (18 October 2001). Nature, 409.

7 Aldhous P. (15 November 2001) "Biologists Urged to Address Risk of Data Aiding Bioweapon Design", Nature, 414.

8 Malakoff D. (17 January 2003). "Researchers Urged to Self-Censor Sensitive Data", Science, 299.

9 Check E. (21 February 2002). "Biologists Apprehensive over US Moves to Censor Information Flow", Nature, 415.

${ }^{10}$ Coker R., McKee M. (4 October 2003). "Politics and Science", Lancet, 362.

${ }^{11}$ Delamothe T. (21-28 December 2002). "How Political Should a General Medical Journal Should Be?", British Medical Journal, 325.

${ }^{12}$ Herrera Taracena G.A., "We Cannot Be Apolitical”, British Medical Journal, 326, 12 April 2003.

${ }_{13}^{13}$ Marchetti P. (12 April 2003). "Medical Journals Is No Place for Politics", British Medical Journal, 326.

${ }^{14}$ Roberts I.G. (12 April 2003) "Medical Journals May Have Had Role in Justifying War", British Medical Journal 326.

${ }^{15}$ Greco P. (March 2002) "Comunicare nell'era post-accademica della scienza”, JCOM, 1.

${ }^{16}$ Journal Editors and Authors Group (21 February 2003) "Statement on Scientific Publication and Security", Science, 299.

${ }^{17}$ Check E. (29 August 2002) "US Prepares Ground for Security Clampdown", Nature, 418.

${ }^{18}$ Couzin J., (12 July 2002) “Active Poliovirus Baked from Scratch”, Science, 297.

${ }^{19}$ Public Library of Science. (15 February 2003) Plos Statement on Censorship.

${ }^{20}$ Check E. (16 January 2003). "US Officials Urge Biologists to Vet Publications for Bioterror Risk”, Nature, 421.

${ }^{21}$ Check E. (20 February 2003). "Journals Tighten up on Biosecurity", Nature, 421.

${ }^{22}$ Petro J.B., Ralman D.A. (12 December 2003). "Understanding Threats to Scientific Openness", Science, 302

${ }^{23}$ Sturloni G. (June 2003) “Autocensura preventiva”, JCOM, 5.

${ }^{24}$ Dalton R., (1 November 2001) "Science Marshalled To Cut Bioterror Confusion”, Nature, 414.

${ }^{25}$ Gibbons J.H., Houghton A., Morgan M.G. (14 September 2001). "Improving Science and Technology Advice for Congress", Science, 293.

${ }^{26}$ (13 July 2000) “A Health Warning On Bioterrorism”, Nature, 406.

${ }^{27}$ Couzin J. (2 August 2002). “A Call for Restraint on Biological Data Science”, Science, 297.

\section{Author}

Maria Chiara Montani graduated at Parma University with a degree in Chemistry. She got a Master in Science Communication at the International School for Advanced Studies (Sissa) in Trieste, Italy.

Now, she is working as a scientific journalist for a newspaper "La Gazzetta di Parma" and is collaborating with Publishing Houses such as Zanichelli, De Agostini, Loescher for Chemistry and Biology School Tests. She has been teaching Science Communication at the University of Parma for two years. Email: machi.m@libero.it. 